\title{
A Dynamic Pricing Model for a Maritime Transportation Service Provider
}

\author{
Seda Ŭgurlù ${ }^{\dagger}$ \\ Istanbul Technical University, Department of Industrial Engineering, \\ Istanbul, 34367, Turkey \\ Özlem Coşgun \\ Fatih University, Department of Industrial Engineering, \\ Istanbul, 34500, Turkey \\ Yeliz Ekinci \\ Dogus University, Department of Industrial Engineering, \\ Istanbul, 34722, Turkey \\ Received 12 November 2011 \\ Accepted 27 July 2012
}

\begin{abstract}
In this study, the dynamic pricing optimization problem faced by the maritime transportation service provider company is considered. The aim is to find optimal prices for each journey for each level of unsold seats by using probabilistic dynamic programming. Conjoint analysis is used to identify the consumer behavior in case of price changes to the current product, namely journey. The optimal policies show the necessity of applying dynamic pricing policy instead of fixed pricing and the diversification of optimal policies under different conditions.
\end{abstract}

Keywords: Dynamic pricing, conjoint analysis, multinomial logit model, maritime transportation

\section{Introduction}

Revenue management is a business principle that balances supply and demand to control price and/or inventory availability in order to maximize revenue and profit growth ${ }^{1}$. Although its impact depends on the size of the company and the complexity of its operations, an estimate of $2 \pm 10 \%$ in revenue increase has been directly attributed with revenue management ${ }^{2}$. The development of Internet distribution channels has created both opportunities and challenges in pricing. It has allowed price changes to be made quickly and frequently with negligible costs and therefore prices have become more visible to consumers because comparison shopping can be done with the click of a mouse. Therefore, nowadays it has become important to develop operational models that incorporate customer choice ${ }^{3}$. At this point, revenue management with dynamic pricing models come into the scene.

There is a vast literature dealing with the revenue management and dynamic pricing problems of different industries, especially airline, freight, and tourism markets. However there has been no study conducted for maritime intercity passenger transportation industry to the best of our knowledge. This market shows some similarities to the airlines market, but it has some differences as well due to the level of competition in the market, prices and conventions of the consumers. First of all, the frequency of a customer of using the service is greater while the prices are lower, therefore the demand/price structure is significantly different. On the other hand, the number of seats is fixed similar to the airlines industry but different from the retailing industry; since in the retailing industry new orders can be given for satisfying the demand. This study tries to fill the gap in the literature by developing a dynamic pricing model for maritime intercity passenger transportation industry.

The paper includes six sections. Literature review follows this section and then problem description is presented. In section 4, our methodology, which involves demand estimation, conjoint analysis and dynamic pricing model subsections, is described. In section 5, the case study is explained and finally conclusion and future research are discussed.

\section{Literature Review}

We recommend the interested readers to refer to the very good review of Bitran and Caldentey and the textbook of Talluri and van Ryzin about pricing models for revenue management ${ }^{4,5}$. As well as, a good literature survey on pricing and inventory

\footnotetext{
†SedaUğurlu, sedayanik@itu.edu.tr, Istanbul Technical University, Department of Industrial Engineering,
} Istanbul, 34367 Turkey 
decisions has been presented by Elmaghraby and Keskinocak $^{6}$. However, some revenue management models, especially for the transportation industry are reviewed below in order to see the contribution of this study compared to the previous ones.

Dynamic pricing problems for a fixed stock of a single item sold in a finite selling horizon have attracted considerable attention in the revenue management literature. The problem of dynamic pricing of seats sold in the transportation industry is an example of these types of problems. A new analytical procedure for joint pricing and seat allocation problem considering demand forecasts, number of fare classes, and aircraft capacities has been investigated ${ }^{1}$. They use polyhedral graph theoretical approach for optimization and show that it achieves significant computer time savings when compared to a general purpose integer programming commercial software. Another approach is to formulate an intensity control model of the dynamic pricing problem ${ }^{7}$. Using this approach, several structural properties have been derived. A similar problem with non-homogeneous demand has been considered to show that dynamic pricing policies can have a significant impact on revenue when demand is non-homogeneous ${ }^{8}$. In a recent study, a Markov decision process formulation of a dynamic pricing problem for multiple substitutable flights between the same origin and destination has been developed taking into account customer choice among the flights ${ }^{3}$.

The bulk of the published literature on revenue management in the transport industry deals with the airline industry ${ }^{1,3,9,10,11}$. However, the application of the principles of revenue management in railway industry has also been investigated in the literature. In the study of Bharill and Rangaraj, the strategy of overbooking is interpreted in terms of waitlist management by the railway company and cancellation action of customers; finally revenue management through differential pricing is suggested as a means to increase revenue on average $^{12}$. On the other side, Maddah et al. develop a discrete-time dynamic capacity control model for a cruise ship characterized by multiple constraints on cabin and lifeboat capacities, which is the first study developed for cruise ships ${ }^{13}$. To the best of our knowledge, this study is a first attempt that models dynamic pricing for a maritime intercity passenger transportation company.

There are many studies investigating the role of competition for revenue management. Competition models consider that customers can choose their supplier, in this case, the supplier has to determine how to control the inventory level. In this stream of literature, $\mathrm{Li}$ and $\mathrm{Ji}$-Hua develop a continuous-time dynamic pricing model for two competitive flights with stochastic control theory and game theory, and find that equilibrium strategy is proved to be better $^{8}$. Yong-bo et al. study the joint dynamic pricing for two parallel flights, which are owned by the same airline company and are scheduled at different times ${ }^{14}$. In their model, potential passengers make ticket-purchasing choices based on the combination of departure times and selling prices. However, in the case of our study, the market is monopolistic similar to the most of the research on dynamic pricing ${ }^{7,8,15,16}$.

Both revenue management and dynamic pricing models need to characterize the demand. Studies commonly propose Gamma, Normal shapes and Poisson function for demand distributions ${ }^{1,14,9,3}$. On the other hand, some of the studies make some assumptions for modeling demand under different price levels based on previous data ${ }^{14,17,13,9}$, some use price elasticity functions derived from previous data $^{12,11}$.

In our study, the market is monopolistic and the price has been fixed up to this time. Therefore, there is no previous data which shows the relation between different prices and demand. Due to this situation a survey was prepared to derive these relations. The survey was conducted with a representative sample of passengers of the transport line and offered as a contribution of this study since the aim is to estimate the demand under different prices via learning the perceptions of the passengers instead of making some assumptions.

\section{Problem Description}

This study deals with the dynamic pricing problem of ferry lines departing from Istanbul. The ferry transportation in Istanbul is offered by only one service provider and the market is monopolistic. Therefore, the model that will be developed does not include competition. The service provider currently applies fixed pricing and considers applying dynamic pricing due to its several benefits presented in Section 1 and 2. The realized demands in the past years show that the demand varies based on the season (summer/winter), weekdays/weekends and purpose of the trip (tourism or business). Moreover, a survey is conducted in order to retrieve the demand and price elasticities of passengers since there is no previous data about the relation between demand and the price. Conjoint analysis is used to process the survey data and the probability that passengers willing to pay a specific price under different conditions (season, weekdays/weekends and purpose of the trip) are found. Finally, utilizing these findings and the past sales data, a dynamic pricing model is built in order to see the optimal policies under different conditions. We have employed a Probabilistic Dynamic Programming method to find the optimal pricing policies. The optimal policies show the necessity of applying dynamic pricing instead of fixed pricing and show the diversification of optimal policies under different conditions. 


\section{Methodology}

This section includes the demand estimation via conjoint analysis by using multinomial logit model. As well, the dynamic pricing model for our problem which includes probabilistic dynamic programming algorithm is explained.

\subsection{Demand forecasting}

Demand forecasting is crucial to any supplier, manufacturer or retailer. In most of the cases, forecasting procedures deal with the demand arising from the actions of the customers. Demand results from many individuals making choice decisions choice to buy one firm's products over another, to wait or not to buy at all, to buy more or fewer unit ${ }^{5}$. The supplier may be able to influence the amount and timing of customer demand by altering the price of its product, traditional "marketing mix" variables of product design, promotion, and distribution. On the other hand, for firms, it is not possible to know how customers will behave in a complex, competitive marketplace. The firm's lack of prior knowledge about how the customers will order is the challenge of the forecasting problem.

Many different forecasting techniques can be broadly classified into one of the following four basic categories based on the fundamental approach towards the forecasting problem: Judgmental Approaches, Experimental Approaches, Relational/Causal Approaches, Time Series Approaches. Judgment-based forecasts rely on expert opinion, experience, judgment and intuition. Experimental approaches are mainly employed in the early stages of new product development when it is important to get some estimate of the level of potential demand for the product. A variety of market research techniques are used to this end. Relational/causal approaches are used when a relationship between an existing and new situation can be built. The basic principle is to define some relationships between the explanatory variables (population, income, and so forth) and sales for the existing situation, then use these relations for the new situation as well. Time-series technique is an approach to generate the large number of shortterm, locally disaggregated forecasts. In the time series approach, the data at hand is assumed to consist of a "pattern", which is consistent, and some noise. The time series procedure attempts to capture and model the "pattern" and to ignore the "noise". In our study, we have chosen to employ a relational approach since we may identify the relation between the present price level and the demand using the responses obtained from the choice based survey. Then using this knowledge, we aimed to figure out the demand that may result under different price levels integrating with the past sales data. Our approach included a two-stage demand generation procedure. In the first stage, we have used the past sales data in order to identify the average level of demand for different times of journeys described with the time of day and the day of week. We have also specified the variation of the level of demand by the variance of the past sales data. Then, in the second stage, we have used a probabilistic model of individual customer utility which is named in the literature as random utility model (RUM). Using the RUM approach, we developed a choice model with the survey data and calculated the price elasticities.

In RUM, the choices of the customers are related to a representative component and a random component. Representative component $u_{j}$ includes the utility of an alternative which can be defined by the observer with the product attributes. Random part of the utility which can not be observed by the researcher is identified as a mean-zero random component $\xi_{j}$. Thus, the overall utility is formulated as (1).

$U_{j}=u_{j}+\zeta_{j}$

When the representative component is assumed to be linear with respect to the product attributes, it is defined as (2).

$u_{j}=\beta^{\mathrm{T}} x_{j}$

where $\beta$ is a vector of parameters and $x_{j}$ is a vector of product attribute values of alternative $j$.

When the random component, $\boldsymbol{\xi}_{j}$, is identified as random variables with a Gumbel distribution, the random utility models are named as multinomial logit models (MNL). The MNL models are commonly used in the literature due to the simple probability formulation derived. In MNL models, the probability that an alternative $j$ is chosen from a set $S \subseteq N=\{1,2, \ldots, n\}$ that contains $j$ is given by (3).

$\mathrm{P}_{j}(S)=\frac{e^{u_{j}}}{\sum_{i \in S} e^{u_{i}}}$

Since choice probabilities are formulated as a function of observed variables, one may formulate the extent to which these probabilities change in response to a change in some observed factor. The change in the probability alternative $i$ given a change in an observed factor, $x_{i}$, entering the representative utility of that alternative (and holding the representative utility of other alternatives constant) is formulated as in (3).

$\frac{\partial u_{i}}{\partial x_{i}} x_{i}\left(1-\mathrm{P}_{i}\right)$

If representative utility is linear in $x_{i}$ with coefficient $\beta_{x}$, the elasticity becomes $\beta_{x} x_{i}\left(1-\mathrm{P}_{i}\right)$. 
Using the formulation of price elasticity, we estimate the change in demand for various price levels. We employ conjoint analysis technique to specify the multinomial logit model parameters and price elasticity. Then, we simulate the reactions of consumers to price changes.

\subsection{Conjoint analysis}

Conjoint analysis is a technique for measuring trade-offs for analyzing survey responses concerning preferences and intentions to buy. Moreover, it is a method for simulating how consumers might react to changes in current products or to new products introduced ${ }^{18}$. In our setting, we aim to identify the consumer behavior in case of price changes to the current product. Thus, conjoint analysis is used as a method to understand how consumers respond to buy or not to buy journey tickets under a price increase or decrease. Using this knowledge, we have been able to identify the change in the level of demand to different journey alternatives.

We have employed a choice-based conjoint (CBC) experiment to analyze intercity maritime travelers' preferences for ferry journeys defined by three product attributes: journey's day of week, journey's time of day and ticket fare. Choice-based conjoint analysis is a stated preference value revelation technique that is based on allowing consumers to make choices from a set of experimentally designed products defined by a bundle of a product's attributes $^{19}$. The results are derived from an approach using a multinomial logit model. We have focused on the main effects of the attributes in the additive utility function of the formulated logit model .

Experimental design and questionnaire construction are the most fundamental, but also the most challenging parts of choice-based conjoint analysis $^{20,21,22}$. In our case, we have undergone discussions with domain experts in order to identify the key attributes and the levels of the attributes that should be included in the analysis. The product attributes and the levels of the products are given in Table 1. A fractional factorial design with 2 types of 9-run profile was used in construction of the CBC experimental questionnaire. Statistically, a full factorial design would have required $5 \times 6 \times 5=150$ unique combinations of journey attributes. However, asking respondents to select their most preferred attribute combination from 150 possibilities would not have been possible.
Table 1. Attributes and attribute levels of ferry journeys

\begin{tabular}{|c|c|}
\hline Attributes & Levels \\
\hline \multirow[t]{5}{*}{ Day of Week } & Monday-Tuesday-Wednesday \\
\hline & Thursday \\
\hline & Friday \\
\hline & Saturday \\
\hline & Sunday \\
\hline \multirow[t]{6}{*}{ Time of Day } & 06.00-08.00 \\
\hline & $08.00-10.00$ \\
\hline & $10.00-16.00$ \\
\hline & $16.00-18.00$ \\
\hline & $18.00-21.00$ \\
\hline & $21.00-24.00$ \\
\hline \multirow[t]{5}{*}{ Fare } & $40 \%$ Increase \\
\hline & $20 \%$ Increase \\
\hline & Present Fare \\
\hline & $20 \%$ Decrease \\
\hline & 40\%Decrease \\
\hline
\end{tabular}

Thus, a fractional factorial design has been employed. In the survey, none option has been included in the alternatives presented to the respondents. An example of a conjoint question is given in Table 2.

Using the proposed choice-based conjoint model, we have estimated price elasticities for various journey alternatives and then by using probabilistic dynamic programming we presented the optimal pricing schemes for intercity maritime transportation. The estimates of the price elasticity allow generating demand level potentials based on various price levels. We find that the price elasticity differs between various levels of product attributes, day of week and time of day. We identified segments of consumers based on the purpose of their travel, namely work travels and leisure travels. We have also shown that price elasticity differs depending on the travel purpose of the traveler. 
Table 2. An example of a conjoint question

\begin{tabular}{cc} 
Option \#1 & Option \#2 \\
\hline & \\
Sunday & Saturday
\end{tabular}

Time: $10.00-16.00$

Time: $18.00-21.00$

$20 \%$ less than present fare $\quad 20 \%$ more than present fare

Option \#3

Option\#4

Thursday

None

Time: 21.00 - 24.00

Present fare

A maritime transportation company could use such information to target its customers based on their future value potential to the firm. We use the estimates of parameters obtained by conjoint analysis to characterize consumer demand for maritime transportation and to design optimal pricing schemes that maximize gross contribution for a monopolist market.

\subsection{Dynamic Pricing}

In our study, we consider a class of multistage problems called a dynamic pricing optimization problem faced by a maritime transportation service provider company in Istanbul. Passengers make a reservation before their journey. The fullness of the seats and time are important attributes to determine the prices. Therefore the aim is to find optimal prices for each journey for all number of seats. As a result, the system state $S_{t}$ is defined with the number of seats at time $t$. The actions $a_{t}$ are the prices and the decision $a_{t}^{*}$ at time $t$ will be given according to these actions that will be evaluated at time $t$. In this case the possible action set $A\left(S_{t}\right)$ of the $S_{t}$ state is as in (5) if there are $k$ prices observed.

$$
A\left(S_{t}\right)=\left\{a_{1 t}, a_{2 t}, \ldots, a_{k t}\right\} .
$$

Then, the policy $\pi$ is formed from the decision given for each day $\pi=\left\{a_{1}^{*}, a_{2}^{*}, \ldots, a_{T}^{*}\right\}$. Demand is normally distributed with mean $\mu$ and standard deviation $\sigma(N \sim(\mu, \sigma))$. In this model, demand is "lost" if not fulfilled in the same time period and doesn't have a cost. We don't consider the correlations amongst the products which are mentioned as maritime transportation service provider in this paper and the other transportation vehicles such as car and bus. Therefore, the substitute demand does not have effect on maritime demand. However, if empty seats are available, they have a cost. Therefore, the total demand for each journey at time $t$ is simply the number of seats sold. When demand $D_{t}$ is appeared, the system state $S_{t}$ which is the number of seats changes into $S_{t+1}=\max \left(0, S_{t}-D_{t}\right)$.

We use Probabilistic Dynamic Programming to solve the problem. The aim of this stochastic optimization problem is to determine the optimal policy given in (6).

$$
\max _{\pi} E\left[\sum_{t=1}^{T} V^{\pi}\left(S_{t}, a_{t}^{\pi}\right)\right]
$$

where $V$ is the value function for state $S_{t}$. The optimality function is as follows which is known as Bellman Equation:

$$
V_{t}\left(S_{t}\right)=\max _{a_{t} \in A\left(S_{t}\right)}\left(C\left(S_{t}, a_{t}\right)+\gamma \sum_{S_{t+1} \in S} p\left(S_{t+1} \mid S_{t}, a_{t}\right) V_{t+1}\left(S_{t+1}\right)\right)
$$

$V_{t}\left(S_{t}\right)$ is the maximum expected discounted reward that can be earned during $t$ periods if the state of the current period is $S_{t}, C\left(S_{t}, a_{t}\right)$ is the cost ( or revenue) function of state $S_{t}$ under decision $a_{t}$ and $p($.$) denotes the probability of next$ period's state $S_{t+1}$ given the current state is $S_{t}$. Moreover, $\gamma$ is the discount factor between two periods. This general model qualifies to be a Markov decision process because it possesses the Markovian property that characterizes any Markov process. In particular, given the current state and decision, any probabilistic statement about the future of the process is completely unaffected by providing any information about the history of the process. This Markovian property holds here since (i) we are dealing with a Markov chain, (ii) the new transition probabilities depend on only the current state and decision. Furthermore, we used discounted cost criterion which becomes preferable to the average cost criterion because the discounted cost criterion can readily be adapted to dealing with a finite-period Markov decision process where the Markov chain will terminate after a certain number of periods. 
In dynamic programming, we usually proceed by stepping backward in time, where we have to solve equation (7) for each state $S_{t}$. So, at the end of the period the value function $V_{T}\left(S_{T}\right)$ takes only the value of cost of empty seats. Moreover, the value of being in state $S_{t}$ in any period $t$, denoted by $V_{t}\left(S_{t}\right)$ is formed from two parts: immediate reward $C_{t}\left(S_{t}, a_{t}\right)$ and discounted cost-to-go value function $\gamma \sum_{S_{t+1} \in S} p\left(S_{t+1} \mid S_{t}, a_{t}\right) V_{t+1}\left(S_{t+1}\right)$ shown in (7). Then dynamic programming algorithm tries to find optimal action for each state $S_{t}$ by using (8)

$$
a_{t}^{*}=\underset{a_{t} \in A\left(S_{t}\right)}{\arg \max }\left\{C_{t}\left(S_{t}, a_{t}\right)+\gamma \sum_{S_{t+1} \in S} p\left(S_{t+1} \mid S_{t}, a_{t}\right) \bar{V}_{t}\left(S_{t+1}\right)\right\}
$$

Furthermore, the reward function $C_{t}\left(S_{t}, a_{t}\right)$ is the profit obtained from the difference of the sales and the cost of empty seats

$$
C_{t}\left(S_{t}, a_{t}\right)=D_{t} * a_{t}-\max \left(0, S_{t}-D_{t}\right) * c_{e t}
$$

where $c_{e t}$ denotes the cost of empty seats at time $t$.

\section{Case Study}

In this study, we investigated the pricing policy of a maritime transportation service provider which operates on 19 lines, and serving 32 points with 10 fast ferries (vehicle-pass fast ferry), 25 seabuses (only passenger), and 17 conventional vehicle-passenger ferries. We analyzed two vehiclepassenger ferry lines namely Istanbul-Bandirma and Istanbul-Bursa. The illustration of these ferry lines are given in Figure 1.

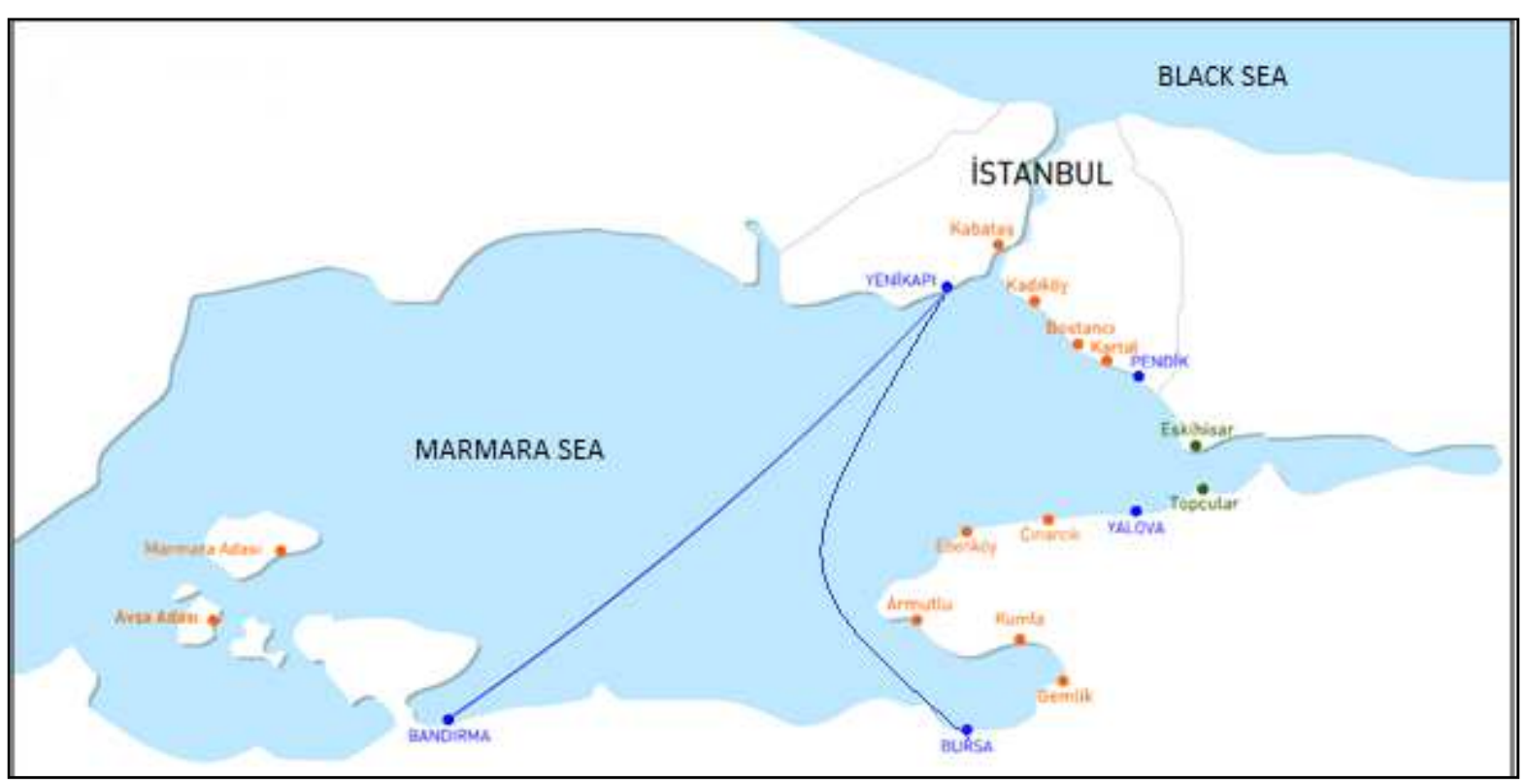

Fig. 1. Ferry lines used in our case study

\subsection{Data analysis for demand estimation}

Demand estimations for these lines were made based on sections 4.1 and 4.2. We used the past sales data in order to identify the average level of demand and the variation of demand. The dataset includes past two years sales data which comprises the day of trip, time of trip, the number of sold seats and the season of the trip. The average number of sold seats and the standard deviation with respect to different days of week and seasons for the two ferry lines, to Bandirma and to Bursa are given in Table 3.

Past sales data show that the demand of ferry line operating between Istanbul-Bursa in week days is usually higher than the demand in weekend. This is due to the fact that this line is commonly used for work travel. Furthermore, it is seen that the demand of ferry line operating between Istanbul-Bandirma in summer is higher than it is in winter since Bandirma is a stop on the way to the seaside resorts. 
Table 3. Mean and standard deviation of number of sold seats.

\begin{tabular}{|c|c|c|c|c|c|c|c|c|}
\hline & \multicolumn{4}{|c|}{ Istanbul-Bandırma } & \multicolumn{4}{|c|}{ Istanbul-Bursa } \\
\hline & \multicolumn{2}{|c|}{ Winter } & \multicolumn{2}{|c|}{ Summer } & \multicolumn{2}{|c|}{ Winter } & \multicolumn{2}{|c|}{ Summer } \\
\hline Day of Week & Mean & $\begin{array}{l}\text { Standard } \\
\text { Deviation }\end{array}$ & Mean & $\begin{array}{l}\text { Standard } \\
\text { Deviation }\end{array}$ & Mean & $\begin{array}{l}\text { Standard } \\
\text { Deviation }\end{array}$ & Mean & $\begin{array}{l}\text { Standard } \\
\text { Deviation }\end{array}$ \\
\hline Monday & 148 & 36.18 & 195 & 15.22 & 156 & 34.05 & 188 & 31.20 \\
\hline Tuesday & 160 & 30.90 & 198 & 8.96 & 195 & 26.65 & 202 & 24.54 \\
\hline Wednesday & 159 & 33.97 & 197 & 10.47 & 203 & 18.17 & 201 & 23.36 \\
\hline Thursday & 159 & 33.31 & 197 & 13.77 & 197 & 22.04 & 197 & 33.56 \\
\hline Friday & 150 & 37.84 & 190 & 19.60 & 177 & 34.89 & 188 & 41.56 \\
\hline Saturday & 164 & 35.34 & 198 & 2.66 & 174 & 37.58 & 190 & 47.48 \\
\hline Sunday & 127 & 41.77 & 188 & 23.07 & 96 & 39.12 & 144 & 67.53 \\
\hline Total & 153 & 37.37 & 195 & 13.48 & 180 & 38.13 & 187 & 43.52 \\
\hline
\end{tabular}

The past sales data belongs to the present ticket fare. Since demand is sensitive to price changes, we need to identify the level of change in demand with respect to the price. In order to find the demand level for different prices, we have employed a conjoint analysis. For this aim, a survey was conducted with 3170 passengers. This survey included conjoint questions and additional questions related to demographics and travel types. The information regarding experimental design and conjoint questions were given in Section 4.2.

The results of conjoint analysis are obtained by using MNL models in Sawtooth Software. The parameters for each level of each product attribute are derived using the responses to the conjoint questions. Then, contribution of each product attributes' level to the utility is calculated. The difference between the highest and lowest utility contribution of a product attribute determines the importance of that attribute. The importances of the three product attributes for the two ferry lines are given in Figure 2.

The ticket fare for both of the lines is found to be the most important attribute. The second important attribute differs among the lines. For Bursa, time of day is more important than the day of week while day of week is more important for Bandirma passengers.

We have chosen to analyze a week day and weekend for both lines. We have also investigated the demand levels for a specific trip, namely early morning trip. In this setting, we have simulated the choice probabilities using the parameters obtained in conjoint analysis. Specifically, we have fixed the day of week and time of day and then calculated the choice probabilities for different price levels. In Table 4, the choice probabilities belonging to different destinations, namely Bursa and Bandirma, for weekday and weekend are given with respect to different price levels.

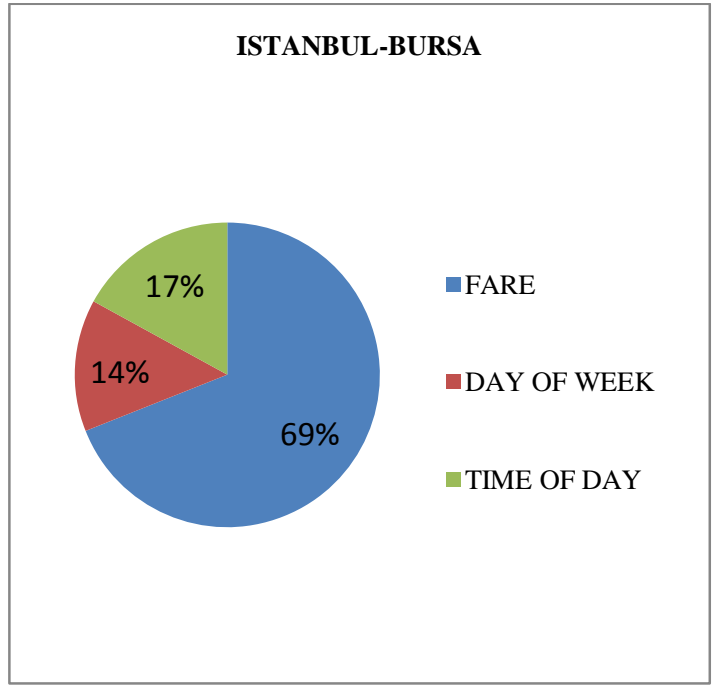

ISTANBUL-BANDIRMA

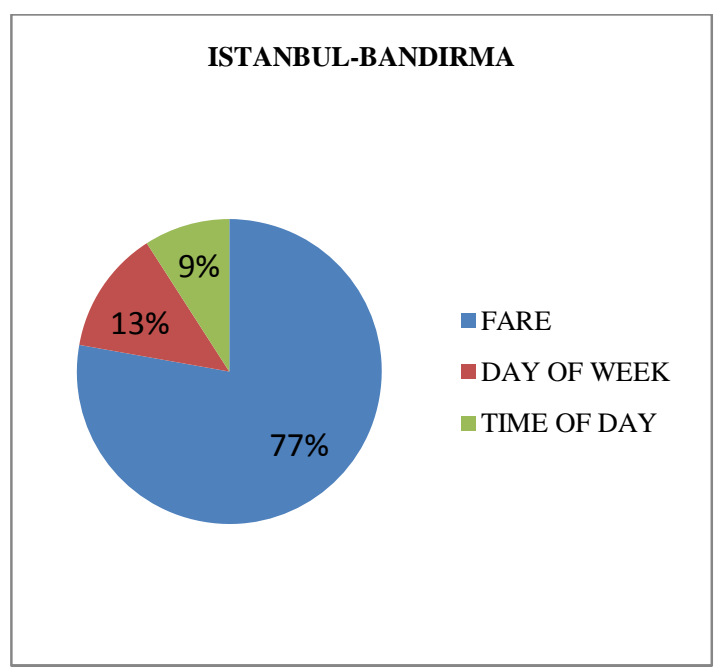

Fig. 2. The importances of attributes for the two ferry lines 
Table 4. Choice probabilities belonging to Bursa and Bandırma destinations

\begin{tabular}{ccccccc}
\hline Destination & Day of week & $\mathbf{4 0 \%}$ Decrease & $\begin{array}{c}\mathbf{2 0 \%} \\
\text { Decrease }\end{array}$ & $\begin{array}{c}\text { Present } \\
\text { Fare }\end{array}$ & $\begin{array}{c}\mathbf{2 0 \%} \\
\text { Increase }\end{array}$ & $\begin{array}{c}\mathbf{4 0 \%} \\
\text { Increase }\end{array}$ \\
\hline Bursa & Weekday & $34.82 \%$ & $26.10 \%$ & $15.50 \%$ & $12.31 \%$ & $11.27 \%$ \\
Bursa & Weekend & $45.72 \%$ & $33.81 \%$ & $19.33 \%$ & $14.97 \%$ & $13.55 \%$ \\
Bandirma & Weekday & $31.03 \%$ & $27.35 \%$ & $15.64 \%$ & $12.55 \%$ & $13.43 \%$ \\
Bandirma & Weekend & $19.58 \%$ & $17.49 \%$ & $10.84 \%$ & $9.08 \%$ & $9.58 \%$ \\
\hline
\end{tabular}

Since the dataset includes the past sales data with the present fare, we calculated the relative demand for the other price levels using this information. Afterwards, it was necessary to detail these demand levels based on the purchase time. According to the survey results, passengers usually purchase their tickets at most one week before the trip. Therefore, the demand belonging to each 7 days before the trip day have been chosen as the time range to be employedfor further use in dynamic pricing model. This specification is made based on the answers to the survey questions about the purchase time. Finally, the overall demand for each price level was decomposed to seven days.

\subsection{Numerical results for dynamic pricing model}

The dynamic pricing model which was explained in section 4.3 was run for 8 cases; for Bursa and Bandirma destination points, for Summer and Winter seasons, and for weekends/weekdays using the data calculated in the previous section. The model results are expected to differ among these 8 experiments since demand structures and price/demand elasticities of each case are different from each other. Bursa is a city which is visited more in winter due to being a tourism centre of skiing. Additionally Bursa is one of the biggest cities in Turkey and is one of the business centres of Turkey. Therefore the demand of Bursa ferries is relatively high. Bandirma is a city which is generally visited in summer due to being a tourism centre of summer holidays since it has nice beaches. However there is a considerable demand for this city at all times since it connects Istanbul to southern cities. Table 5 shows the seven days dynamic pricing model results for a pre-determined demand path; 5, 9, 15, 20, 45, 60, 72 seats.

Comparing the optimal prices for Bursa and Bandirma under the conditions of winter and weekend, we see that on the fifth day the price for Bursa is higher than Bandirma. The reason for this finding is that demand for Bursa is generally higher in winter since people travel from Istanbul to Bursa for skiing. Therefore it was expected to see a slightly higher price for Bursa compared to Bandirma.

The optimal pricing for winter-weekdays tickets is the same for Bursa and Bandirma. The optimal prices occurred as the lowest price (60 TL) for 4 days beginning from the first day that the tickets are offered for sale, increasing the price on the fifth day by $15 \mathrm{TL}$ and selling the tickets at the highest price (120 TL) on the last 2 days. This finding is due to the indifference among the demand structures and demand-price elasticity of these two lines for winter-weekdays.

A general result derived from winter policies is that these four policies are similar to each other for weekends and weekdays, except for Bandırmaweekend. For Bandirma-weekend there is no price increase on the fifth day. This difference is because of the low demand for Bandirma at weekends in winter. People do not prefer visiting Bandırma in this time period. However the demand is not low in weekdays since people visit Bandirma for business in weekdays.

The optimal pricing policy of summer-weekend tickets is significantly different for Bursa and Bandirma. There is a price increase on the second day, a decrease on the third day and again an increase on the fourth day for Bandirma. However there is only one price increase for Bursa tickets which is on the sixth day. The optimal prices for Bandirma are generally higher since Bandirma is highly preferred in summers for swimming. The demand for Bursa tickets is lower in summerweekends since people travel to Bursa for mostly business reasons in summer. This point is also the main reason of increasing the Bursa-summerweekday tickets one day earlier than Bandirma.

Some important findings are derived from the comparisons of optimal policies of weekday versus weekend tickets. For example, weekend prices of Bandirma-summer tickets are higher than weekday tickets since people go to holidays generally at weekends and high demand results in higher prices. Additionally, the optimal pricing policy for Bursasummer tickets suggests price increase earlier for weekdays than weekends. This is a result of higher demand for Bursa on weekdays due to high number of travels for business reasons. Similarly winter versus summer comparisons result in significant facts. An example to this point is Bursa-weekend tickets. The optimal pricing suggests price increase on the fifth day for winter tickets while it suggests price increase on the sixth day for summer tickets. 
Table 5. Optimal dynamic pricing policies

\begin{tabular}{|c|c|c|c|c|c|c|c|}
\hline \multicolumn{4}{|c|}{$\begin{array}{c}\text { Bursa-winter-weekdend } \\
\text { Unsold }\end{array}$} & \multicolumn{4}{|c|}{ Bandırma-winter-weekend } \\
\hline Time & Demand & Seats & Price (TL) & Time & Demand & Seats & Price (TL) \\
\hline 1 & 5 & 200 & 60 & 1 & 5 & 200 & 60 \\
\hline 2 & 9 & 195 & 60 & 2 & 9 & 195 & 60 \\
\hline 3 & 15 & 186 & 60 & 3 & 15 & 186 & 60 \\
\hline 4 & 20 & 171 & 60 & 4 & 20 & 171 & 60 \\
\hline 5 & 45 & 151 & 75 & 5 & 45 & 151 & 60 \\
\hline 6 & 60 & 106 & 120 & 6 & 60 & 106 & 120 \\
\hline 7 & 72 & 46 & 120 & 7 & 72 & 46 & 120 \\
\hline \multicolumn{4}{|c|}{ Bursa-winter-weekday } & Time & $\begin{array}{l}\text { Bandırma } \\
\text { Demand }\end{array}$ & $\begin{array}{r}\text { Ater-weel } \\
\text { Unso } \\
\text { Seats } \\
\end{array}$ & Price (TL) \\
\hline 1 & 5 & 200 & 60 & 1 & 5 & 200 & 60 \\
\hline 2 & 9 & 195 & 60 & 2 & 9 & 195 & 60 \\
\hline 3 & 15 & 186 & 60 & 3 & 15 & 186 & 60 \\
\hline 4 & 20 & 171 & 60 & 4 & 20 & 171 & 60 \\
\hline 5 & 45 & 151 & 75 & 5 & 45 & 151 & 75 \\
\hline 6 & 60 & 106 & 120 & 6 & 60 & 106 & 120 \\
\hline 7 & 72 & 46 & 120 & 7 & 72 & 46 & 120 \\
\hline \multicolumn{4}{|c|}{$\begin{array}{c}\text { Bursa-summer-weekend } \\
\text { Unsold }\end{array}$} & \multicolumn{4}{|c|}{$\begin{array}{c}\text { Bandırma-summer-weekend } \\
\text { Unsold }\end{array}$} \\
\hline Time & Demand & Seats & Price (TL) & Time & Demand & Seats & Price (TL) \\
\hline 1 & 5 & 200 & 60 & 1 & 5 & 200 & 60 \\
\hline 2 & 9 & 195 & 60 & 2 & 9 & 195 & 75 \\
\hline 3 & 15 & 186 & 60 & 3 & 15 & 186 & 60 \\
\hline 4 & 20 & 171 & 60 & 4 & 20 & 171 & 75 \\
\hline 5 & 45 & 151 & 60 & 5 & 45 & 151 & 75 \\
\hline 6 & 60 & 106 & 120 & 6 & 60 & 106 & 120 \\
\hline 7 & 72 & 46 & 120 & 7 & 72 & 46 & 120 \\
\hline \multicolumn{4}{|c|}{ Bursa-summer-weekday } & \multicolumn{4}{|c|}{ Bandırma-summer-weekday } \\
\hline Time & Demand & Seats & Price (TL) & Time & Demand & Seats & Price (TL) \\
\hline 1 & 5 & 200 & 60 & 1 & 5 & 200 & 60 \\
\hline 2 & 9 & 195 & 60 & 2 & 9 & 195 & 60 \\
\hline 3 & 15 & 186 & 75 & 3 & 15 & 186 & 60 \\
\hline 4 & 20 & 171 & 75 & 4 & 20 & 171 & 75 \\
\hline 5 & 45 & 151 & 75 & 5 & 45 & 151 & 75 \\
\hline 6 & 60 & 106 & 120 & 6 & 60 & 106 & 120 \\
\hline 7 & 72 & 46 & 120 & 7 & 72 & 46 & 120 \\
\hline
\end{tabular}

As demand for Bursa tickets is higher in winters due to skiing aimed holidays, passengers are willing to pay higher prices.

Similarly, Bandırma-weekend ticket prices are higher in summer than winter. As demand for Bandirma tickets is higher in summers due to swimming aimed holidays, passengers are willing to pay higher prices.
Moreover, a general comparison of winter-weekday tickets and summer-weekday tickets show that price increase is suggested earlier for summer than winter. This finding is due to the relatively high number of people travelling in summer since annual holidays are mostly used in summers. 


\section{Conclusion \& Future Research}

In this study, we consider a class of multistage problems called the dynamic pricing optimization problem faced by the maritime transportation service provider company in Istanbul. To the best of our knowledge, this study is a first attempt that models dynamic pricing for a maritime public transportation company. The study deals with the case of ferry lines of a maritime transportation service provider which operates in Istanbul. There exists only one service provider of ferry transportation in Istanbul and the market is monopolistic, therefore our model does not include competition. Since the service provider currently applies fixed pricing policy, we consider applying dynamic pricing due to its several benefits. The realized demands in the past years show that the demand varies based on the season (summer/winter), weekdays/weekends and purpose of the trip (tourism or business).

In a dynamic pricing model, demand forecasts for each price level are required. However, there is no previous data which shows the relation between different prices and demand. Because of this reason, a survey was prepared and conducted with 3170 passengers to derive this relation. This survey study is a contribution of this paper since it tries to estimate the demand under different prices -via learning the perceptions of the passengers- instead of making some assumptions which is the approach used in most of the studies in the literature. The demand belonging to different price levels was estimated via conjoint analysis by using past sales data and survey results. Finally, utilizing these inputs, adynamic pricing model is built in order to see the optimal policies under different conditions (for Bursa and Bandırma destination points, for Summer and Winter seasons, and for weekends/weekdays) and it is solved by Probabilistic Dynamic Programming method. The optimal policies give us an idea about the necessity of applying dynamic pricing policy instead of fixed pricing and show us the diversification of optimal policies under different conditions.

In fact, the two destination points are different from each other in their demand structures since Bandirma destination is usually used for summer holidays and Bursa is usually visited for work travels and winter holidays. Therefore, the optimal policies were expected to be different as well. The experimental results supported this idea by finding optimal prices higher for Bandırma in summers and higher for Bursa in winters. Another finding supporting this fact is the higher prices for Bursawinter-weekends compared to Bandırma-winterweekends. An additional finding about higher number of work travels to Bursa concludes in higher prices for weekday tickets.

The methodologies used in this study and the experimental results show us how to apply a dynamic pricing model to a service provider company which currently uses fixed pricing policy under a monopolistic market. For further research, competition with different means of transport can be included to the model since there is no competitor is valid for maritime transport. On the other side, utility function which is formulated only with main-effects of the attributes for demand estimation may be investigated using more complex constructions of MNL, such as a multiplicative model for the overall utility or the presence of interaction effects in the utility function.

The performance of dynamic programming model is well for a not very large state space like in our case study which is the number of seats. When the state space is very large and multidimensional, it is almost impossible to solve optimally which is called as "curse of dimesionality" and it requires approximation algorithms to solve such problems. But in our model, the state is one dimensional and the state space is not very large. As a result, our model has a well performance.

\section{References}

1. Kuyumcu, A. and Garcia-Diaz, A., A polyhedral graph theory approach to revenue management in the airline industry, Computers and Industrial Engineering 38, (2000), 375-396.

2. Feldman, J. M., Getting serious on pricing, Air Transport World 31 (10), (1994), 56-60.

3. Zhang, D. and Cooper, W.L., Pricing substitutable flights in airline revenue management, European Journal of Operational Research 197, (2009), 848861.

4. Bitran, G., Caldentey, R., An overview of pricing models for revenue management. Manufacturing and Service Operations Management 5 (3), (2003), 203-229.

5. Talluri, K., van Ryzin, G.,, The Theory and Practice of Revenue Management. (Kluwer Academic Publishers, Boston, 2004).

6. Elmaghraby, W., Keskinocak, P.,, Dynamic pricing in the presence of inventory considerations: Research overview, current practices, and future directions. Management Science 49 (10), (2003), 1287-1309.

7. Gallego, G., van Ryzin, G., Optimal dynamic pricing of inventories with stochastic demand over finite horizons. Management Science 40(8), (1994), 999-1020.

8. Zhao, W. and Zheng, Y. S., Optimal dynamic pricing for perishable assets with nonhomogeneous demand. Management Science 46 (3), (2000), 375388.

9. Li, L. and Ji-hua, P. Dynamic Pricing Model for Airline Revenue Management under Competition, Systems Engineering Theory \& Practice 27(11), (2007), 15-25.

10. Graf, $M$ and Kimms, A., An option-based revenue management procedure for strategic airline alliances, European Journal of Operational Research, 215, (2011), 459-469. 
11. Gorin, $\mathrm{T}$ and Belobaba, P., Impacts of entry in airline markets: effects of revenue management on traditional measures of airline performance, Journal of Air Transport Management 10, (2004), 259-270.

12. Bharill, R. and Rangaraj, N., Revenue management in railway operations: A study of the Rajdhani Express, Indian Railways, Transportation Research Part A, 42, (2008), 1195-1207.

13. Maddah B., Moussawi-Haidar, L., El-Taha, M. and Rida, H., Dynamic cruise ship revenue management, European Journal of Operational Research, 207, (2010), 445-455.

14. Yong-bo, X., Jian, $\mathrm{C}$ and Xiao-ling, L., Joint Dynamic Pricing for Two Parallel Flights based on Passenger Choice Behavior, Systems Engineering Theory \& Practice 28(1), (2008), 46-55

15. Chatwin R E. Optimal dynamic pricing of perishable products with stochastic demand and a finite set of prices. European Journal of Operational Research, 125, 2000: 149-174.

16. Feng Y, Xiao B. A continuous-time yield management model with multiple prices and reversible price changes. Management Science, 46(5), (2000), 644-657.

17. Friesz, T.L., Mookherjee, R., Holguin-Veras, J. and Rigdon, M.A. (2008). Dynamic pricing in an urban freight environment, Transportation Research Part B 42 (2008) 305-324.

18. Green, P.E., Krieger A.M., Wind, Y., Thirty years of conjoint analysis: Reflections and prospects, Interfaces, 31(3), (2001), 56-73.

19. Louviere, J., Conjoint analysis modeling of stated preferences: a review of theory, methods, recent developments and external validity, Journal of Transport Economics and Policy, 22, (1988), 93-119

20. Anderson, D. and Wiley, J. (1992) Efficient choice set designs for estimating availability cross-effect designs, Marketing Letters, 3, 357-70.

21. Lazari, A. and Anderson, D. (1994) Designs of discrete choice set experiments for estimating both attribute and availability cross effects, Journal of Marketing Research, 31, 375-83.

22. Miguel, F. S., Ryan, M. and McIntosh, E. (2000) Applying conjoint analysis in economic evaluations: an application to menorrhagia, Applied Economics, $32,823-33$ 